See discussions, stats, and author profiles for this publication at: https://www.researchgate.net/publication/319181500

\title{
Modeling Fitness Variable Responses To Training In Prepubescent Children
}

Article in The Journal of Strength and Conditioning Research • August 2017

DOI: 10.1519/JSC.0000000000002201

CITATION

1

6 authors, including:

Ana Ruivo Alves

Polytechnic Institute of Beja

22 PUBLICATIONS 20 CITATIONS

SEE PROFILE

(2) Henrique P. Neiva

Universidade da Beira Interior

85 PUBLICATIONS 274 CITATIONS

SEE PROFILE
Polytechnic Institute of Guarda 37 PUBLICATIONS 147 CITATIONS

SEE PROFILE

Célia Nunes

Universidade da Beira Interior 90 PUBLICATIONS 236 CITATIONS

SEE PROFILE

Some of the authors of this publication are also working on these related projects:

Pacing and Soccer Training View project

Strength and Conditioning and Swimming performance View project 
Modeling fitness variable responses to training in prepubescent children

Running head: Regression linear model and prepubescent children

Ana R. Alves ${ }^{1}$, Carlos Marta ${ }^{3,4}$, Henrique P. Neiva ${ }^{1,2}$, Célia Nunes ${ }^{6,7}$, Mikel Izquierdo ${ }^{5}$, Mário C. Marques ${ }^{1,2}$

${ }^{1}$ University of Beira Interior. Department of Sport Sciences, Covilhã, Portugal

${ }^{2}$ Research Center in Sport Sciences, Health Sciences and Human Development, CIDESD, Portugal

${ }^{3}$ Guarda Polytechnique Institute. Department of Sport Sciences, Guarda, Portugal

${ }^{4}$ Research Unit for Inland Development, UDI, Guarda, Portugal

${ }^{5}$ Department of Health Sciences, Public University of Navarre, Navarre, Spain

${ }^{6}$ University of Beira Interior. Department of Mathematics, Covilhã, Portugal

${ }^{7}$ Center of Mathematics and Applications, CMA-UBI, Portugal

Corresponding Author and address:

Mikel Izquierdo, $\mathrm{PhD}$

Department of Health Sciences

Public University of Navarra (Navarra) SPAIN

Campus of Tudela

Av. de Tarazona s/n. 31500 Tudela (Navarra) SPAIN

Tel + 34948417876

mikel.izquierdo@gmail.com 


\section{ABSTRACT}

The aim of this study was to determine strength and oxygen uptake $\left(\mathrm{VO}_{2} \mathrm{max}\right)$ performances according to different training program intervention design with 8-weeks duration in prepubescent children through a multiple linear regression models. Two hundred and fortyfive healthy prepubescent children (aged $10.9 \pm 0.5$ years) were randomly assigned to a specific training program (strength training only $-\mathrm{S}$; aerobic training only $-\mathrm{A}$; intra-session aerobic and strength training - AS; intra-session strength and aerobic training - SA; or concurrent training performed in different sessions - CT) or a control group (no training regimen - C). It was possible to develop indirect predictive models for each training method, by including each variable pre-training, body fat percentage and body mass index. The models provided explained $82 \%$ of variance in the $\mathrm{VO}_{2} \max , 98 \%$ in the $1 \mathrm{~kg}$ ball-throw, $96 \%$ in the $3 \mathrm{~kg}$ ball-throw, $92 \%$ in the counter-movement jump, $93 \%$ in the standing long jump and $98 \%$ in the $20 \mathrm{~m}$ sprint performances. This novel approach to training evaluation and control aims to provide a tool to allow professionals to calculate changes with a high confidence level (CI 95\%), to control gains and to choose the best training methodology to apply according to the defined purposes. The results of this study could be a great support to teachers, coaches and professionals providing important tools to improve the efficacy and individualization of training.

Key words: concurrent training, explosive, linear regression, youth. 


\section{INTRODUCTION}

Several studies have reported that concurrent training can be highly effective for improving strength and aerobic fitness simultaneously $(16,25)$ in children. Concurrent training is commonly defined as a combination of strength (S) and aerobic (A) training, performed either in the same training session or separately on alternating days, often limiting the recovery between subsequent exercise sessions $(7,8,11,12,31)$. To date, physical education professionals have used this training approach as an efficient and motivational method for children to improve health-related parameters and to gain good physical activity habits (4). Moreover, schools could provide an excellent setting to enhance and promote physical activity by implementing safe training programs $(20,22)$.

More recently, our lab $(3,4)$ contributed to this field by showing that different types of concurrent training (strength exercise and aerobic training, either in the same training session or in different sessions; and aerobic training followed by strength exercise vs. strength training followed by aerobic exercise) are equally effective for training-induced explosive strength, depending on program priorities. However, it still difficult for practitioners not only to choose the best training design but also to predict and identify training standards for strength and aerobic enhancement in a school environment. In fact, to the best of our knowledge, no study has tried to predict the possible gains or decreases in strength and aerobic performance in a concurrent training context. This not only could help to implement the best training "formula" in order to achieve physical fitness goals but also could provide more details on how each subject responds to the training and allows a comparison of individual progress with previously established standards and goals. Therefore, the aim of this study was to determine strength and maximal oxygen uptake $\left(\mathrm{VO}_{2} \mathrm{max}\right)$ performances 
according to different training program intervention design with 8-weeks duration in prepubescent children through a multiple linear regression models. Our hypothesis was that it was possible to predict models that would have different responses based on training program interventions, explaining the relationship between strength, cardiovascular and anthropometrics variables in the prepubescent children performance.

\section{METHODS}

\section{Experimental Approach to the Problem}

The purpose of this study was to determine strength and $\mathrm{VO}_{2}$ max performances according to different training program intervention design (strength training only $-\mathrm{S}$; aerobic training only - A; intra-session aerobic and strength training - AS; intra-session strength and aerobic training - SA; concurrent training performed in different sessions - CT; or a control group C) with 8-weeks duration in prepubescent children through a multiple linear regression models.

\section{Subjects}

Two hundred and forty-five healthy prepubescent children (aged $10.9 \pm 0.5$ years) from a school cluster (Guarda, Portugal) were randomly assigned to a specific training program (S, A, AS, SA, or CT) or a control group (C, no training regimen) for 8 weeks. The height and body mass of the entire sample was as follows: $1.4 \pm 0.08 \mathrm{~m}$, and $39.8 \pm 9.0 \mathrm{~kg}$, respectively. The inclusion criteria were children aged 9 to 12 years (in $5^{\text {th }}$ or $6^{\text {th }}$ grade) without a chronic paediatric disease or orthopaedic limitation and without regular extra-curricular physical activity (i.e., practice of a sport at an academy). 
Before data collection and the beginning of the training, each participant reported any health problems, physical limitations, physical activity habits and training experiences for the last 6 months. Thereafter, maturity levels based on Tanner staging (35) were self-assessed, and to minimize the effects of growth, only children that were self-assessed in Tanner stages I-II were selected. No subject had regularly participated in any form of training program prior to this experiment. Efforts were made to collect a sample for making comparable groups. All participants and their parents/guardians were informed about study procedures as well as possible benefits and risks. The written informed consent was obtained from parents/ guardians of all participants. The study was approved by the Institutional Review Board of the University of Beira Interior and procedures were in accordance with the latest version of the Declaration of Helsinki.

\section{Procedures}

Sample Procedures

Two hundred and forty-five healthy children recruited from a Portuguese public high school were randomly assigned to 5 experimental groups and 1 control group. The assigned groups were determined by a chance process (a random number generator on a computer) and could not be predicted. This procedure was established according to the "CONSORT" statement. The participants were randomly assigned into 1 of 6 intervention arms. Randomization was performed using R software version 2.14 (R Foundation for Statistical Computing).

\section{Training Procedures}

The training programs consisted of a 10-min warm-up period with low to moderate intensity exercises (e.g., running, sprints, stretching and joint specific warm-up). Joint-rotations included slow circular movements, both clockwise and counter-clockwise, until the entire 
joint moved smoothly. Stretching exercises included back and chest stretches, shoulder and side stretches, wrist, waist, quadriceps, groin, and hamstring stretches. At the end of the training sessions, all subjects performed 5 min of static stretching exercises such as kneeling lunges, ankle over knee, rotation and hamstrings.

After the warm-up period, the A group performed a 20-m shuttle run exercise only. The $S$ group performed strength training only, comprising 1 and $3 \mathrm{~kg}$ medicine ball throws, box jumps $(0.3$ to $0.5 \mathrm{~m})$, vertical jumps over a $0.3 \square 0.5 \mathrm{~m}$ hurdle and sets of 30 to $40 \mathrm{~m}$ of sprints. The SA group performed the same strength training and then a $20-\mathrm{m}$ shuttle run exercise, while the AS group performed a 20-m shuttle run exercise and then strength training. Finally, the CT group performed strength training, and in an alternate session (on the next day) performed a 20-m shuttle run after the warm-up. After 4 weeks of training, the A, SA, AS, and CT groups were reassessed with a 20-m shuttle run test to readjust the volume and intensity of the 20-m shuttle run exercise. Each training session lasted approximately 45 min (aerobic group only), 15 min (strength group only) and 60 min (concurrent training groups performed in the same session). It is also important to mention that concurrent training performed in different sessions did strength training (15 minutes) alternate with aerobic training (45 minutes) in different days (strength-aerobic-strength-aerobic). The rest period between sets was 1 min and that between exercises was 2 min.

Before the start of the training, subjects completed two familiarization sessions to practice the drill and routines they would further perform during the training period (i.e., power training exercises and 20-m shuttle run test). The predicted $\mathrm{VO}_{2}$ max was obtained through the MultiStage Fitness Test (MSFT) as described by Léger and colleagues (17). Participants jogged or ran in a straight line between two lines $20 \mathrm{~m}$ apart while keeping pace with pre-recorded audio signals. The initial speed was $8.5 \mathrm{~km} /$ hour and increased by $0.5 \mathrm{~km} / \mathrm{hour}$ each minute. 
The test ended if the participant failed to reach the end lines in time with the audio signals on two consecutive occasions or when the subject stopped because of self-reported fatigue. With the results obtained on MSFT we used the Léger' table (17) to acquire the predictive $\mathrm{VO}_{2} \mathrm{max}$ values from maximal shuttle run speed, stage and age. Throughout the pre- and experimental periods, the subjects reported their non-involvement in additional regular exercise programs for developing or maintaining strength and endurance performance besides institutional regular physical education classes. A more detailed analysis of the program can be found in Table 1.

(Table 1 about here)

The experimental groups were assessed for changes in strength (chest 1 and $3 \mathrm{~kg}$ medicine ball throw, standing long jump, counter movement vertical jump, and $20 \mathrm{~m}$ sprint running) and cardiovascular parameters $\left(\mathrm{VO}_{2} \mathrm{max}\right)$ before and after 8 weeks of training. The study design and training program were developed based in specific studies conducted in prepubescent children $(3,4,21,22)$, and the knowledge of an experienced coach and researcher.

\section{Testing Procedures}

Anthropometric $\_$Measurements. All anthropometric variables were assessed according to international standards for anthropometric assessment (19). Body mass and body fat percentage of the subjects were measured when the subjects were in underwear and did not have shoes and metallic objects (e.g., earrings, bracelets, rings, watches), using electronic scales (Tanita® BC544, Tokyo, Japan) with a low technical error of measurement (TEM= $0.51 \%$ ). Height was measured using a mechanical stadiometer platform $\left(\right.$ Seca $^{\circledR} 214$, Hamburg, Germany; TEM=0.01\%). BMI was calculated as the body weight in kilograms 
divided by the square of the height in meters. Weight status categories were defined as having a BMI above the age and sex-specific thresholds of the IOTF (13).

Medicine Ball Throwing. This test was performed according to the protocol described by Mayhew et al. (23). The subjects were seated with the backside of their trunk touching a wall. They were required to hold medicine balls (Bhalla International - Vinex Sports, Meerut India) that weighed $1 \mathrm{~kg}$ (Vinex, model VMB-001R, perimeter $0.72 \mathrm{~m}$ ) and $3 \mathrm{~kg}$ (Vinex, model VMB-003R, perimeter $0.78 \mathrm{~m}$ ) with their hands (abreast of chest) and throw the ball forward for the maximum possible distance. Hip inflection was not allowed, nor was withdrawal of the trunk away from the wall. Three trials were given, and the furthest throw was measured (in $\mathrm{cm}$ ) from the wall to the first point at which the ball made contact with the floor. One minute of rest was provided between the 3 trials. The intraclass correlation coefficients (ICC) for the $1 \mathrm{~kg}$ and $3 \mathrm{~kg}$ medicine ball throwing data were both $\approx 0.98$.

Standing Long Jump. This test was assessed using the EUROFIT test battery (1). The participants stood with their feet slightly apart (toes behind a starting line) and jumped as far forward as possible. Three trials were given, and the furthest distance was measured (in $\mathrm{cm}$ ) from the starting line to the heel of the foot nearest to this line. The standing long jump has shown an ICC of 0.94 .

Counter Movement Vertical Jump. This test was conducted on a contact mat that was connected to an electronic power timer, control box and handset (Globus Ergojump, Italy). From a standing position, with their feet shoulder-width apart and hands placed on the pelvic girth, the subjects performed a counter movement with their legs before jumping. Such movement makes use of the stretch-shorten cycle in which the muscles are pre-stretched 
before shortening in the desired direction (18). The subjects were informed that they should try to jump vertically as high as possible. Each participant performed three jumps with a 1 min recovery between attempts. The highest jump (in $\mathrm{cm}$ ) was recorded. The counter movement vertical jump has shown an ICC of 0.91 .

20-meter Sprint Running. On a 20-m length track, the subjects were required to cover the distance in the shortest time possible. The time (in s) to run $20 \mathrm{~m}$ was obtained using photocells (Brower Timing System, Fairlee, VT, USA). Three trials were performed, and the best time scored (seconds and hundredths) was registered. The sprint running (time) has shown an ICC of 0.97.

\section{Statistical Analysis}

Statistical analyses were performed using Statistical Package for Social Sciences (SPSS) $\mathrm{v} 22.0^{\circledR}$ for Windows and statistical significance was set at $\mathrm{p} \leq 0.05$. Standard statistical methods were used to calculate the means and standard deviations to describe the data. After check that no assumptions underlying the analysis of residues have been violated (normality, independence and homogeneity of variances) it was possible to predict indirect methods for explosive strength and maximal oxygen uptake variables after each training program chosen through the multiple linear regression model. It was considered the stepwise method. We applied the multiple linear regression since the aim of this study was to evaluate the children performance on the post-test (in respect to explosive strength and maximal oxygen uptake variables) as a function of their baseline values, training program intervention, body fat percentage and body mass index. The normality was verified by the Kolmogorov-Smirnov test. For the homogeneity of variances, the scatterplot of standardized predicted values versus studentized residuals was performed. In order to check the independence, the Durbin-Watson 
Statistics was calculated. The assumption of no extreme values was also verified. The $95 \%$ confidence interval (CI 95\%) was calculated for all estimated variables on the regression model. The data set was splitted into two equal sized sub sets and cross validation, considering the holdout method, was conducted to test if there is no overfitting.

\section{RESULTS}

Table 2 provides descriptive statistics of the independent variables inserted in the standard model for each variable. It was only considered the data that verified all assumptions underlying the regression analysis.

(Table 2 about here)

To verify whether the independent variables were significantly predictive or not to obtain the results of dependent variables (post-test) a multivariate linear regression analysis was performed. Thus, it was possible to estimate the linear regression equations to predict the gains in each variable after 8 weeks and according to the training methodology used.

In Table 3 it can be observed that the null hypothesis in which the coefficient equals zero is rejected at the $95 \%$ confidence level. Therefore, we have sufficient evidences to conclude that each of these variables were significant in the post training performances. Based on this we obtained the following regression equations to each training program (Table 4).

(Table 3 about here)

(Table 4 about here) 
The different training programs explained $82 \%$ of variance in the $\mathrm{VO}_{2} \mathrm{max}, 98 \%$ in the $1 \mathrm{~kg}$ ball-throw, $96 \%$ in the 3kg ball-throw, $92 \%$ in the CM Jump, 93\% in the SL Jump and $98 \%$ in the $20 \mathrm{~m}$ sprint performances.

The results presented in Table 5 suggest that there's no overfitting, since the correlation coefficients are positive and large enough and do not present a big difference between both sub sets. So, we may to conclude that the presented analyses may be generalized.

(Table 5 about here)

\section{DISCUSSION}

The aim of this study was to determine strength and $\mathrm{VO}_{2}$ max performances according to different training program intervention design with 8-weeks duration in prepubescent children through a multiple linear regression models. The resulting models explained $82 \%$ of the variance in the $\mathrm{VO}_{2} \max , 98 \%$ in the $1 \mathrm{~kg}$ ball-throw, $96 \%$ in the $3 \mathrm{~kg}$ ball-throw, $92 \%$ in the CM jump, $93 \%$ in the SL jump and $98 \%$ in the $20 \mathrm{~m}$ sprint performance, with inputs of the pre-training value for each variable, body fat percentage (BFP) and body mass index (BMI). With the results obtained, it was possible to develop indirect predictive models for each training method. These equations serve as a novel approach to training evaluation and control, providing important tools to help professionals improve the efficacy and individualization of training.

Throughout the years, several studies have presented different training programs to improve physical fitness. Strength training has the potential to improve muscle strength, endurance, and power $(3,4,26,27,28,29,30)$, while aerobic training is suggested to improve 
cardiorespiratory fitness (16). Moreover, recent research has suggested that concurrent strength and aerobic training can improve muscular and cardiorespiratory fitness simultaneously, especially in children $(3,4,12,33)$. In this study verifying the influence of different training programs in prepubescent children, all the analysed variables showed improvements after 8 weeks of aerobic, strength or concurrent training $(3,4)$.

It was quite clear in our previous studies that all of the experimental training programs resulted in improved cardiovascular or/and strength parameters $(3,4)$. Consequently, by using the data collected, it was possible to develop an indirect method to evaluate explosive strength and $\mathrm{VO}_{2}$ max variables according to the training methodology applied to the children. It was considered that changes in strength and aerobic variables are strongly related to the baseline values, BFP, BMI, and training methodology used (14). The analysis of the relationships included the training programs as independent variables, which is in itself a novelty in this type of study.

The different equations explained each change in $1 \mathrm{~kg}$ ball-throw, $3 \mathrm{~kg}$ ball-throw, SL jump, CM jump, and $20 \mathrm{~m}$ sprints by more than $90 \%$, which reveals their accuracy and reliability. The explained variance of $\mathrm{VO}_{2} \max$ was lower but still sufficient to support the predictive model. It can be stated that qualitatively, a high predictive value for strength and cardiovascular variables was verified. Even so, a range between $20 \%\left(\mathrm{VO}_{2} \max \right)$ and $2 \%$ (1 $\mathrm{kg}$ ball-throw and $20 \mathrm{~m}$ sprints) of the change cannot be explained by the included variables. Perhaps predictability would increase if a more specific apparatus were used for evaluation (e.g., breath-by-breath oxygen measures) or if other measurements were included, such as changes in maturity, motor control, genetics or psychology $(5,34,36)$. 
One of the goals of physical activity professionals working with children should be to develop their strength and cardiovascular fitness so that they can reach the standard values for healthy youth. Usually, several assessments are performed at the beginning of the school year to evaluate physical fitness. Based on those results, teachers should plan a training program to improve the weakest capacities and to maintain the higher-level ones. Moreover, it is known that different kinds of training develop each strength and/or aerobic parameter differently. For instance, aerobic training programs achieve better results in $\mathrm{VO}_{2} \mathrm{max}$, while the AS, CT and SA programs seem to be more efficient in developing explosive strength (3, 4). Thus, with the suggested prediction equations and previous evaluations, the teacher will be able to understand which program is the best to implement. In addition, the teacher can adjust each training program individually to each student according to their needs and using variables that are easy to collect and have a natural meaning to design, control and evaluate the training process. A practical example, if a prepubescent child is assessed at the beginning of the school year (i.e., $\mathrm{VO}_{2} \max$ ) and the results in baseline are $\mathrm{VO}_{2} \mathrm{max}=42.3 \mathrm{ml} \cdot \mathrm{kg}^{-1} \cdot \mathrm{min}^{-1}$ and body fat percentage $=21.29 \%$, the teacher can predict (using the formulas in Table 3 ) that performing 8 weeks of intra-session strength and aerobic training would result in a $\mathrm{VO}_{2} \mathrm{max}$ of $44.32 \mathrm{ml} \cdot \mathrm{kg}^{-1} \cdot \mathrm{min}^{-1}$. Instead, if performing intra-session aerobic and strength training the $\mathrm{VO}_{2}$ max would be $45.39 \mathrm{ml} \cdot \mathrm{kg}^{-1} \cdot \mathrm{min}^{-1}$, if performing concurrent strength and aerobic training in different sessions, it would be $45.45 \mathrm{ml} \cdot \mathrm{kg}^{-1} \cdot \mathrm{min}^{-1}$, if performing aerobic training only, it would be $45.72 \mathrm{ml} \cdot \mathrm{kg}^{-1} \cdot \mathrm{min}^{-1}$, and without training the $\mathrm{VO}_{2}$ max would stay similar $\left(42.77 \mathrm{ml} \cdot \mathrm{kg}^{-1} \cdot \mathrm{min}^{-1}\right) . ”$

Predictive models are not new in sports science research. However, until now, most of them were developed to explain acute performance responses based on biomechanical, physiological or/and anthropometric measures $(6,24)$ or to predict aerobic capacity 
$\left(\mathrm{VO}_{2} \max \right)$ or maximal strength $(1 \mathrm{RM})(15,32)$. In contrast, the present study aimed to understand and predict the responses to different training program interventions. This approach aims to provide a tool to allow professionals to calculate changes with a high confidence level (CI 95\% is also provided in the results if needed), to control gains and to choose the best training methodology to apply according to the defined purposes. At the end of the program, the same variable could be evaluated again and compared with the expected results to identify responders or even to understand the children's commitment to the program. There is a wide inter-individual variability in response to exercise training that under the same stimulus, some subjects may achieve positive benefits after training (i.e., responders), while others exhibit a worsened or unchanged response and are thus termed nonresponders (10). In a study conducted by Alvarez and colleagues (2) applied in school children were found several metabolic, body composition, blood pressure, and performance improvements independent of an early or normal maturation or the prevalence of nonresponders.

In conclusion, the model based on baseline values of strength and cardiovascular variables, $\mathrm{BMI}, \mathrm{BFP}$ and the training program selected is appropriate to explain changes in $\mathrm{VO}_{2} \mathrm{max}, 1$ $\mathrm{kg}$ and $3 \mathrm{~kg}$ ball-throw, SL jump, CM jump, and $20 \mathrm{~m}$ sprint in prepubescent children (aged 9-12 years). These results are novel findings in this area, and the equations presented could be a great support to teachers, coaches, professionals to estimate and predict the physical fitness gains expected during 8 weeks of training (twice per week, i.e., the typical frequency of physical education lessons). Nevertheless, further research is needed to improve these data by including longer durations of training or even other physiological variables that could help to explain the effects obtained. 


\section{PRACTICAL APPLICATIONS}

The indirect predictive models for each training method were developed, being a novel approach to training evaluation and control. These equations could be of great interest for teachers, coaches, professionals, allowing to estimate and to predict the changes in the physical fitness of children during 8-weeks of training (twice-a-week, the same as the physical education lessons). Moreover, these equations providing to abovementioned professionals pertinent information (i.e., relationship between variables and training method, according to the measurement) to decide which program training is more effective according to the children' purposes/needs. With this novel approach, it is also possible to improve the efficacy and individualization of training.

\section{ACKNOWLEDGEMENTS}

This project was supported by the National Funds through FCT - Portuguese Foundation for Science and Technology (UID/DTP/04045/2013) - and the European Fund for Regional Development(FEDER) allocated by European Union through the COMPETE 2020Programme (POCI-01-0145-FEDER-006969) - competitiveness and internationalization (POCI). 


\section{REFERENCES}

1. Adam, C., Klissouras, V., Ravassolo, M., Renson, R., Tuxworth, W., Kemper, H., Vanmechelen, W., Hlobil, H., Beunen, G., Levarlet-Joye, H. \& Vanlierde, A. (1988). Eurofit: Handbook for the Eurofit Test of Physical Fitness. Rome: Edigraf Editoriale Gráfica.

2. Alvarez, C., Ramírez-Campillo, R., Ramírez-Vélez, R., \& Izquierdo, M. (2017). Effects of 6-weeks high-intensity interval training in schoolchildren with insulin resistance: influence of biological maturation on metabolic body composition, cardiovascular and performance non-responses. Frontiers in Physiology, 8, 444.

3. Alves, A.R., Marta, C.C., Neiva, H.P., Izquierdo, M., \& Marques, M.C. (2015). Concurrent training in prepubescent children: The effects of 8 weeks of strength and aerobic training on explosive strength and $\mathrm{VO}_{2}$ max. Journal of Strength \& Conditioning Research, 30 (7), 2019-32.

4. Alves, A.R., Marta, C.C., Neiva, H.P., Izquierdo, M., \& Marques, M.C. (2016). Does intra-session concurrent strength and aerobic training order influence traininginduced explosive strength and $\mathrm{VO}_{2} \max$ in prepubescent children? Journal of Strength \& Conditioning Research, 30(12), 3267-3277.

5. Armstrong, N., Barker, A.R., \& McManus, A.M. (2015). Muscle metabolism changes with age and maturation: How do they relate to youth sport performance? British Journal of Sports Medicine, 49(13), 860-864.

6. Barbosa T.M., Costa, M., Marinho, D.A., Coelho, J., Moreira, M., \& Silva, A.J. (2010). Modeling the links between young swimmers' performance: energetic and biomechanic profiles. Pediatric Exercise Science, 22(3), 379-391. 
7. Bell, G.J., Syrotuik, D., Socha, T., Maclean, I., \& Quinney, H.A. (1997). Effect of Strength Training and Concurrent Strength and Endurance Training on Strength, Testosterone, and Cortisol. Journal of Strength \& Conditioning Research, 11(1), 5764.

8. Bell, G.J., Syrotuik, D., Martin, T., Burnham, R., \& Quinney, H. (2000). Effect of concurrent strength and endurance training on skeletal muscle properties and hormone concentrations in humans. European Journal of Applied Physiology, 81(5), 418-427.

9. Benson, A.C., Torode, M.E., \& Fiatarone Singh, M.A. (2007). A rational and method for high-intensity progressive resistance training with children and adolescents. Contemporary Clinical Trials, 28(4), 442-450.

10. Bonafiglia, J.T., Rotundo, M.P., Whittall, J.P., Scribbans, T.D., Graham, R.B., \& Gurd, B.J. (2016). Inter-individual variability in the adaptive responses to endurance and sprint interval training: a randomized crossover study. PLOS ONE 11: e 0167790.

11. Cadore, E.L., Pinto, R., Lhullier, F., Correa, C., Alberton, C., Pinto, S., \& Kruel, L. (2010). Physiological effects of concurrent training in elderly men. International Journal of Sports Medicine, 31(10), 689-697.

12. Cadore, E.L., Izquierdo, M., dos Santos, M.G., Martins, J.B., Lhullier, F.L.R., Pinto, R.S., \& Kruel, L.F.M. (2012). Hormonal responses to concurrent strength and endurance training with different exercise orders. Journal of Strength \& Conditioning Research, 26(12), 3281-3288.

13. Cole, T.J., Bellizzi, M.C., Flegal, K.M., \& Dietz, W.H. (2000). Establishing a standard definition for child overweight and obesity worldwide: International survey. BMJ, 320, 1240-1243.

14. Grund, A., Dilba, B., Forberger, K., Krause, H., Siewers, M., Rieckert, H., \& Müller, 
M.J. (2000). Relationships between physical activity, physical fitness, muscle strength and nutritional state in 5- to 11-year-old children. European Journal of Applied Physiology, 82(5-6), 425-438.

15. Hoffman, J.R., \& Kang, J. (2003). Strength changes during an in-season resistancetraining program for football. Journal of Strength \& Conditioning Research, 17(1),109-114.

16. Kang, Y., \& Ratamess, N. (2014). Which Comes First? Resistance Before Aerobic Exercise or Vice Versa? American College of Sports Medicine, 18(1), 9-14.

17. Léger, L.A., Mercier, D., Gadoury, C., \& Lambert, J. (1988). The multistage 20-meter shuttle run test for aerobic fitness. Journal of Sports Sciences, 6 (2), 93-101.

18. Linthorne, NP. (2001). Analysis of standing vertical jumps using a force platform. American Journal of Physics, 69(11), 1198-1204.

19. Marfell-Jones, M., Olds, T., Stewart, A., \& Carter, L. (2006). International Standards for Anthropometric Assessment. Potchefstroom, South Africa: ISAK.

20. Marques, M.C., Zajac, A., Pereira, A., \& Costa, A.M. (2011). Strength training and detraining in different populations: Case studies. Journal of Human Kinetics, (Special Issue): $7-14$.

21. Marta, C.C., Marinho, D.A., Barbosa, T.M., Carneiro, A.L., Izquierdo, M., \& Marques, M.C. (2013a). Effects of body fat and dominant somatotype on explosive strength and aerobic capacity trainability in prepubescent children. Journal of Strength and Conditioning Research, 27(12), 3233-44.

22. Marta, C.C., Marinho, D.A., Barbosa, T.M., Izquierdo, M., \& Marques, M.C. (2013b) Effects of concurrent training on explosive strength and VO $\left({ }_{2} \mathrm{max}\right)$ in prepubescent children. International Journal of Sports Medicine, 34(10), 888-896.

23. Mayhew, J.L., Ware, J.S., Johns, R.A., \& Bemben, M.G. (1997). Changes in upper 
body power following heavy-resistance strength training in college men. International Journal of Sports Medicine, 18(7), 516-520.

24. Morais, J.E., Silva, A.J., Marinho, D.A., Marques, M.C., Batalha, N., \& Barbosa, T.M. (2016). Modelling the relationship between biomechanics and performance of young sprinting swimmers. European Journal of Sport Science, 16(6), 661-668.

25. Pugh, J.K., Faulkner, S.H., Jackson, A.P., King, J.A., \& Nimmo, M.A. (2015). Acute molecular responses to concurrent resistance and high- intensity interval exercise in untrained skeletal muscle. Physiological Reports, 3(4), e12364.

26. Ramírez-Campillo, R., Andrade, D.C., \& Izquierdo, M. (2013). Effects of plyometric training volume and training surface on explosive strength. Journal of Strength and Conditioning Research, 27(10), 2714-2722.

27. Ramírez-Campillo, R., Andrade, D.C., Álvarez, C., Henríquez-Olguín, C., Martínez, C., Báez-SanMartín, E., Silva-Urra, J., Burgos, C., \& Izquierdo, M. (2014). The effects of interest rest on adaptation to 7 weeks of explosive training in young soccer players. Journal of Sports Science \& Medicine, 13(2), 287-296.

28. Ramírez-Campillo, R., Henríquez-Olguín, C., Burgos, C., Andrade, D.C., Zapata, D., Martínez, C., Baez, E.L., Castro-Sepúlveda, M., Peñailillo, L., \& Izquierdo, M. (2015a). Effect of progressive volume-based overload during plyometric training on explosive and endurance performance in young soccer players. Journal of Strength and Conditioning Research, 29(7), 1884-1893.

29. Ramírez-Campillo, R., Burgos, C., Henríquez-Olguín, C., Andrade, D.C., Martínez, C., Álvarez, C., Castro-Sepúlveda, M., Marques, M.C., \& Izquierdo, M. (2015b). Effect of unilateral, bilateral, and combined plyometric training on explosive and endurance performance of young soccer players. Journal of Strength and Conditioning Research, 29(5), 1317-1328. 
30. Rosas, F., Ramírez-Campillo, R., Diaz, D., Abad-Colil, F., Martinez-Salazar, C., Caniuqueo, A., Cañas-Jamet, R., Loturco, I., Nakamura, F.Y., McKenzie, C., Gonzalez-Rivera, J., Sanchezz-Sanches, J., \& Izquierdo, M. (2016). Jump training in youth soccer players: effects of haltere type handheld loading. International Journal of Sports Medicine, 37(13), 1060-1065.

31. Reed, J.P., Schilling, B.K., \& Murlasits, Z. (2013). Acute neuromuscular and metabolic responses to concurrent endurance and resistance exercise. Journal of Strength \& Conditioning Research, 27(3), 793-801.

32. Reynolds, J.M., Gordon, T.J., Robergs, R.A. (2006). Prediction of one repetition maximum strength from multiple repetition maximum testing and anthropometry. Journal of Strength \& Conditioning Research, 20(3), 584-592.

33. Silva, R.F., Cadore, E.L., Kothe, G., Guedes, M., Alberton, C.L., Pinto, S.S., Pinto, R.S., Trindade, G., \& Kruel, L.F. (2012). Concurrent training with different aerobic exercises. International Journal of Sports Medicine, 33(8), 627-643.

34. Schutte, N.M., Nederend, I., Hudziak, J.J., de Geus, E.J., \& Bartels, M. (2016). Differences in adolescent physical fitness: A multivariate approach and meta-analysis. Behaviour Genetics, 46(2), 217-227.

35. Tanner, J.M., \& Whitehouse, R.H. (1976). Clinical longitudinal standards for height, weight, height velocity, weight velocity, and stages of puberty. Archives of Disease in Childhood, 51(3), 170-179.

36. Vandendriessche J.B., Vandorpe, B., Coelho-e-Silva, M.J., Vaeyens, R., Lenoir, M., Lefevre, J., \& Philippaerts, R.M. (2011). Multivariate association among morphology, fitness, and motor coordination characteristics in boys age 7 to 11. Pediatric Exercise Science, 23(4), 504-520. 


\section{Tables}

Table 1 - Training Program Design (sets x repetitions/distances).

\begin{tabular}{|c|c|c|c|c|c|c|}
\hline \multicolumn{7}{|c|}{ Sessions } \\
\hline Exercise & 1 & 2 & 3 & 4 & 5 & 6 \\
\hline $1 \mathrm{~kg}$ _BT & $2 \times 8$ & $2 \times 8$ & $2 \times 8$ & $2 \times 8$ & $2 \times 8$ & $2 \times 8$ \\
\hline 3kg_BT & $2 \times 8$ & $2 \times 8$ & $2 \times 8$ & $2 \times 8$ & $2 \times 8$ & $2 \times 8$ \\
\hline SL & $2 \times 4$ & $2 \times 4$ & $2 \times 4$ & $2 \times 4$ & $2 \times 4$ & $2 \times 4$ \\
\hline $\mathrm{CM}$ & $1 \times 5$ & $1 \times 5$ & $1 \times 5$ & $1 \times 5$ & $2 \times 5$ & $2 \times 5$ \\
\hline $\mathrm{SP}$ & $2 \times 20 \mathrm{~m}$ & $2 \times 20 \mathrm{~m}$ & $2 \times 20 \mathrm{~m}$ & $2 \times 20 \mathrm{~m}$ & $3 \times 20 \mathrm{~m}$ & $3 \times 20 \mathrm{~m}$ \\
\hline 20m Shuttle Run (MAV) & $70 \%$ & $70 \%$ & $70 \%$ & $70 \%$ & $75 \%$ & $75 \%$ \\
\hline \multicolumn{7}{|c|}{ Sessions } \\
\hline Exercise & 7 & 8 & 9 & 10 & 11 & 12 \\
\hline $1 \mathrm{~kg}$ _BT & $2 \times 8$ & $2 \times 8$ & $3 \times 8$ & $3 \times 8$ & $3 \times 8$ & $3 \times 8$ \\
\hline 3kg_BT & $2 \times 8$ & $2 \times 8$ & $2 \times 8$ & $2 \times 8$ & $3 \times 6$ & $3 \times 6$ \\
\hline SL & $2 \times 4$ & $2 \times 4$ & $3 \times 4$ & $3 \times 4$ & $3 \times 4$ & $3 \times 4$ \\
\hline $\mathrm{CM}$ & $2 \times 5$ & $7 x$ & $2 \times 5$ & $2 \times 5$ & $3 \times 5$ & $3 \times 5$ \\
\hline SP & $3 \times 20 \mathrm{~m}$ & $3 \times 20 \mathrm{~m}$ & $3 \times 20 \mathrm{~m}$ & $3 \times 20 \mathrm{~m}$ & $3 \times 30 \mathrm{~m}$ & $3 \times 30 \mathrm{~m}$ \\
\hline 20m Shuttle Run (MAV) & $75 \%$ & $75 \%$ & $75 \%$ & $75 \%$ & $80 \%$ & $80 \%$ \\
\hline Exercise & 13 & 14 & 15 & 16 & & \\
\hline $1 \mathrm{~kg}$ _BT & $3 \times 8$ & $3 \times 8$ & $3 \times 8$ & $3 \times 8$ & & \\
\hline $3 \mathrm{~kg} \_\mathrm{BT}$ & $3 \times 6$ & $3 \times 6$ & $3 \times 6$ & $3 \times 6$ & & \\
\hline SL & $4 \times 4$ & $4 \times 4$ & $4 \times 4$ & $4 \times 4$ & & \\
\hline CM & $3 \times 5$ & $3 \times 5$ & $3 \times 5$ & $3 \times 5$ & & \\
\hline SP & $3 \times 30 \mathrm{~m}$ & $3 \times 30 \mathrm{~m}$ & $3 \times 30 \mathrm{~m}$ & $3 \times 30 \mathrm{~m}$ & & \\
\hline 20m Shuttle Run (MAV) & $80 \%$ & $80 \%$ & $80 \%$ & $80 \%$ & & \\
\hline
\end{tabular}

1kg_BT: chest $1 \mathrm{~kg}$ medicine ball throw (cm), 3kg_BT: chest 3kg medicine ball throw (cm), 20m Shuttle Run (MAV): MAV, maximal individual aerobic volume, CM: counter movement vertical jump (cm), SL: standing long jump (cm), SP: 20-m sprint running (s). 
Table 2 - Descriptive statistics of the independent variables in analysis.

\begin{tabular}{|c|c|c|c|c|c|c|c|}
\hline \multirow{2}{*}{\multicolumn{2}{|c|}{$\begin{array}{c}\mathrm{V}(\mathrm{n}=243) \\
\mathrm{V(ml \cdot \textrm {kg } ^ { - 1 } \cdot \mathrm { min } ^ { - 1 } ) 4 3 . 0 6 \pm 3 . 2 9}\end{array}$}} & 1kg_BT $(n=244)$ & 3kg_BT $(n=244)$ & $\mathrm{SL}(\mathrm{n}=237)$ & $\mathrm{CM}(\mathrm{n}=238)$ & \multicolumn{2}{|c|}{$\mathrm{SP}(\mathrm{n}=241)$} \\
\hline & & $1 \mathrm{~kg} \_B T(\mathrm{~cm}) \quad 345.68 \pm 65.80$ & $226.65 \pm 43.49$ & $129.34 \pm 20.14$ & $\mathrm{CM}(\mathrm{cm}) 22.89 \pm 5.37$ & SP (s) & $4.37 \pm 0.31$ \\
\hline $\mathrm{BMI}\left(\mathrm{kg} \cdot \mathrm{m}^{2}\right)$ & $19.01 \pm 3.16$ & $19.00 \pm 3.16$ & $19.00 \pm 3.16$ & & $18.98 \pm 3.19$ & & $19.02 \pm 3.18$ \\
\hline $\mathrm{BFP}(\%)$ & $21.32 \pm 8.21$ & $21.29 \pm 8.18$ & $21.34 \pm 8.19$ & & $21.31 \pm 8.19$ & & $21.38 \pm 8.23$ \\
\hline$\overline{\mathrm{C}}$ & $\mathrm{N}=44$ & $\mathrm{~N}=44$ & $\mathrm{~N}=43$ & $\mathrm{~N}=40$ & $\mathrm{~N}=43$ & & $\mathrm{~N}=43$ \\
\hline SA & $\mathrm{N}=44$ & $\mathrm{~N}=45$ & $\mathrm{~N}=45$ & $\mathrm{~N}=45$ & $\mathrm{~N}=45$ & & $\mathrm{~N}=45$ \\
\hline AS & $\mathrm{N}=32$ & $\mathrm{~N}=31$ & & $\mathrm{~N}=30$ & $\mathrm{~N}=32$ & & $\mathrm{~N}=32$ \\
\hline $\mathrm{CT}$ & $\mathrm{N}=40$ & $\mathrm{~N}=41$ & & $\mathrm{~N}=40$ & $\mathrm{~N}=36$ & & $\mathrm{~N}=40$ \\
\hline A & $\mathrm{N}=42$ & $\mathrm{~N}=42$ & & $\mathrm{~N}=41$ & $\mathrm{~N}=41$ & & $\mathrm{~N}=41$ \\
\hline S & $\mathrm{N}=41$ & $\mathrm{~N}=41$ & $\mathrm{~N}=41$ & $\mathrm{~N}=41$ & $\mathrm{~N}=41$ & & $\mathrm{~N}=40$ \\
\hline
\end{tabular}

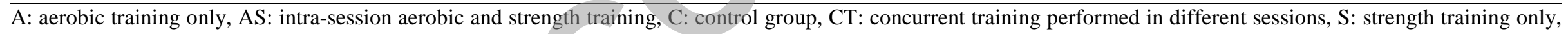
SA: intra-session strength and aerobic training. BMI $\left(\mathrm{kg} \cdot \mathrm{m}^{2}\right)$ : body mass index, BFP (\%): body fat percentage, $1 \mathrm{~kg}$ _BT: chest $1 \mathrm{~kg}$ medicine ball throw (cm), $3 \mathrm{~kg} \_$BT: chest $3 \mathrm{~kg}$ medicine ball throw $(\mathrm{cm}), \mathrm{CM}$ : counter movement vertical jump (cm), SL: standing long jump (cm), SP: 20-m sprint running (s), V: multistage shuttle run (VO ${ }_{2}$ max, $\left.\mathrm{ml} \cdot \mathrm{kg}^{-1} \cdot \mathrm{min}^{-1}\right)$. 
Table 3 - Estimated regression coefficients from linear regression models only for significant variables.

\begin{tabular}{|c|c|c|c|c|c|c|}
\hline Variable & & Estimates & $\mathbf{C I}_{\mathbf{9 5} \%}$ & p-value* & $\mathbf{R}_{\mathbf{a}}{ }^{2}$ & ANOVA $(* *$ p-value $)$ \\
\hline \multirow{7}{*}{$\mathrm{V}_{\text {post }}$} & Constant & 3.859 & $(0.326,7.393)$ & 0.032 & 0.822 & 0.000 \\
\hline & $\mathrm{V}_{\text {pre }}$ & 0.954 & $(0.882,1.027)$ & 0.000 & & \\
\hline & Intra-session strength and aerobic training & 1.547 & $(1.009,2.086)$ & 0.000 & & \\
\hline & Concurrent training performed in different sessions & 2.683 & $(2.074,3.291)$ & 0.000 & & \\
\hline & Intra-session aerobic and strength training & 2.621 & $(1.995,3.246)$ & 0.000 & & \\
\hline & Aerobic training only & 2.952 & $(2.336,3.568)$ & 0.000 & & \\
\hline & $\mathrm{BFP}_{\text {pre }}$ & 0.070 & $(-0.096,-0.044)$ & 0.000 & & \\
\hline \multirow[t]{6}{*}{$1 \mathrm{~kg} \_\mathrm{BT}_{\text {post }}$} & Constant & 0.025 & $(-6.989,7.039)$ & 0.994 & 0.978 & 0.000 \\
\hline & $1 \mathrm{~kg} \_\mathrm{BT}$ pre & 1.009 & $(0.990,1.029)$ & 0.000 & & \\
\hline & Intra-session strength and aerobic training & 17.019 & $(13.407,20.631)$ & 0.000 & & \\
\hline & Strength training only & 17.053 & $(13.334,20.771)$ & 0.000 & & \\
\hline & Concurrent training performed in different sessions & 16.954 & $(13.220,20.688)$ & 0.000 & & \\
\hline & Intra-session aerobic and strength training & 10.615 & $(6.510,14.721)$ & 0.000 & & \\
\hline \multirow[t]{6}{*}{$3 \mathrm{~kg} \_\mathrm{BT} \mathrm{T}_{\text {post }}$} & Constant & 4.610 & $(-1.931,11.151)$ & 0.166 & 0.955 & 0.000 \\
\hline & $3 \mathrm{~kg} \_\mathrm{BT}$ pre & 0.993 & $(0.965,1.021)$ & 0.000 & & \\
\hline & Intra-session strength and aerobic training & 16.484 & $(13.036,19.932)$ & 0.000 & & \\
\hline & Strength training only & 15.143 & $(11.587,18.699)$ & 0.000 & & \\
\hline & Concurrent training performed in different sessions & 15.042 & $(11.482,18.602)$ & 0.000 & & \\
\hline & Intra-session aerobic and strength training & 9.730 & $(5.844,13.615)$ & 0.000 & & \\
\hline \multirow{4}{*}{$\mathrm{CM}_{\text {post }}$} & Constant & 0.440 & $(-4.469,1.349)$ & 0.341 & 0.918 & 0.000 \\
\hline & $\mathrm{CM}_{\text {pre }}$ & 1.015 & $(0.976,1.055)$ & 0.000 & & \\
\hline & Aerobic training only & -0.918 & $(-1.485,-0.351)$ & 0.002 & & \\
\hline & Concurrent training performed in different sessions & 0.670 & $(0.080,1.261)$ & 0.026 & & \\
\hline \multirow[t]{6}{*}{$\mathrm{SL}_{\text {post }}$} & Constant & 5.605 & $(-0.645,11.856)$ & 0.079 & 0.933 & 0.000 \\
\hline & $\mathrm{SL}_{\text {pre }}$ & 1.013 & $(0.974,1.052)$ & 0.000 & & \\
\hline & Intra-session strength and aerobic training & 6.684 & $(4.701,8.667)$ & 0.000 & & \\
\hline & Strength training only & 4.113 & $(2.058,6.167)$ & 0.000 & & \\
\hline & Concurrent training performed in different sessions & 4.030 & $(1.969,6.091)$ & 0.000 & & \\
\hline & $\mathrm{BFP}_{\text {pre }}$ & -0.216 & $(-0.314,-0.119)$ & 0.000 & & \\
\hline \multirow[t]{7}{*}{$\mathrm{SP}_{\text {post }}$} & Constant & -0.036 & $(-0.134,0.062)$ & 0.474 & 0.976 & 0.000 \\
\hline & $\mathrm{SP}_{\text {pre }}$ & 0.998 & $(0.974,1.021)$ & 0.000 & & \\
\hline & Intra-session aerobic and strength training & -0.018 & $(-0.039,0.003)$ & 0.094 & & \\
\hline & Intra-session strength and aerobic training & -0.083 & $(-0.101,-0.065)$ & 0.000 & & \\
\hline & Strength training only & -0.084 & $(-1.103,-0.065)$ & 0.000 & & \\
\hline & Concurrent training performed in different sessions & -0.078 & $(-0.097,-0.059)$ & 0.000 & & \\
\hline & $\mathrm{BFP}_{\text {pre }}$ & 0.002 & $(0.001,0.002)$ & 0.000 & & \\
\hline
\end{tabular}


Table 4 - Regression equations to each training program.

\begin{tabular}{|c|c|c|c|c|c|c|}
\hline \multirow{2}{*}{\multicolumn{2}{|c|}{ Control group }} & \multicolumn{3}{|c|}{ Intra-session strength and aerobicIntra-session aerobic and strength Concurrent training performed } & \multirow[t]{2}{*}{ Aerobic training only } & \multirow[t]{2}{*}{ Strength training only } \\
\hline & & training & training & in different sessions & & \\
\hline$\overline{\mathrm{V}_{\text {post }}}$ & $3.859+0.954 \mathrm{xV}-0.070 \mathrm{xBFP}$ & $5.406+0.954 \times \mathrm{xV}-0.070 \times \mathrm{BFP}$ & $6.48+0.954 x V-0.070 x B F P$ & $6.542+0.954 x$ & $6.811+0.954 \mathrm{xV}-0.070 \mathrm{xBFP}$ & \\
\hline $1 \mathrm{~kg} \_\mathrm{BT}_{\text {post }}$ & st $0.025+1.009 x 1 \mathrm{~kg} \_B T$ & $17.044+1.009 x 1 \mathrm{~kg} \_\mathrm{BT}$ & $10.64+1.009 \times 1 \mathrm{~kg} \_$BT & 16.97 & & $17.078+1.009 x 1 \mathrm{~kg} \_\mathrm{BT}$ \\
\hline $3 \mathrm{~kg} \_\mathrm{BT}_{\text {post }}$ & tit $4.610+0.993 \times 3 \mathrm{~kg} \_B T$ & $20.634+0.993 \times 3 \mathrm{~kg} \_B T$ & $13.192+0.993 \times 3 \mathrm{~kg} \_B T$ & & & $18.65+0.993 \times 3 \mathrm{~kg} \_\mathrm{BT}$ \\
\hline $\mathrm{CM}_{\text {post }}$ & $0.440+1.015 \mathrm{xCM}$ & & & & $-0.478+1.015 x \mathrm{xM}$ & \\
\hline $\mathrm{SL}_{\text {post }}$ & $5.605+1.013 x$ SL-0.216xBFP & $12.289+1.013 \times$ SL-0.216xBFP & & $.013 \times S L-0.216 x B F P$ & & $9.718+1.013 x$ SL-0.216xBFP \\
\hline $\mathrm{SP}_{\text {post }}$ & $-0.036+0.998 \times \mathrm{SP}+0.002 \times \mathrm{BFP}$ & $-0.119+0.998 \times \mathrm{SP}+0.002 \times \mathrm{BFP}$ & $0.054+0.998 \times \mathrm{xP}+0.002 \times \mathrm{BFP}$ & $-0.114+0.998 \times \mathrm{SP}+0.002 \times B F P$ & & $-0.12+0.998 \times S P+0.002 \times B F P$ \\
\hline
\end{tabular}

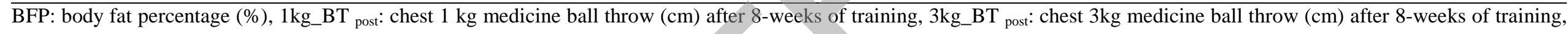

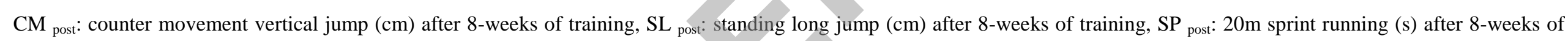

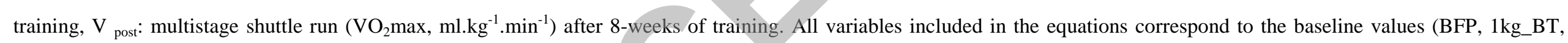

3kg_BT, CM, SL, SP, V). 
Table 5- Cross validation - holdout method

\begin{tabular}{|c|c|c|}
\hline Variable & Testing set ${ }^{\#}$ & Training set ${ }^{\#}$ \\
\hline $\mathrm{V}_{\text {post }}$ & 0.917 & 0.897 \\
\hline $1 \mathrm{~kg} \_\mathrm{BT}$ post & 0.987 & 0.984 \\
\hline $3 \mathrm{~kg} \_\mathrm{BT}$ post & 0.981 & 0.972 \\
\hline $\mathrm{CM}_{\text {post }}$ & 0.962 & 0.955 \\
\hline $\mathrm{SL}_{\text {post }}$ & 0.964 & 0.968 \\
\hline $\mathrm{SP}_{\text {post }}$ & 0.984 & 0.991 \\
\hline
\end{tabular}

\# Pearson correlation coefficient between predicted and observed values. $1 \mathrm{~kg} \_\mathrm{BT}$ : chest $1 \mathrm{~kg}$ medicine ball throw, $3 \mathrm{~kg} \_$BT: chest $3 \mathrm{~kg}$ medicine ball throw, CM: counter movement vertical jump, SL: standing long jump, SP: 20m sprint running, V: multistage shuttle run $\left(\mathrm{VO}_{2} \mathrm{max}\right)$. post- corresponds to the values after 8-weeks of training. 